\title{
Osteonectin (SPARC) Is a Key Regulator of Malignant Pleural Mesothelioma
}

\author{
Fauzia Siddiq ${ }^{1}$, Fulvio Lonardo ${ }^{1}$, Harvey I. Pass ${ }^{2}$, Arun K. Rishi ${ }^{3} \&$ Anil Wali ${ }^{1,4}$ \\ ${ }^{1}$ John D. Dingell VA Medical Center, Departments of Otolaryngology, Surgery, and Karmanos Cancer Institute, \\ Wayne State University, Detroit, MI, USA \\ ${ }^{2}$ Division of Cardiothoracic Surgery, New York University Cancer Center, New York, USA \\ ${ }^{3}$ Department of Oncology, Wayne State University, John D. Dingell VA Medical Center, Research \& \\ Development Section, Detroit, MI, USA \\ ${ }^{4}$ Center to Reduce Cancer Health Disparities, National Cancer Institute, National Institutes of Health, Rockville, \\ MD, USA
}

Correspondence: Arun K. Rishi, Department of Oncology, Wayne State University, John D. Dingell VA Medical Center, Room B4334, Research \& Development Section, 4646 John R. Street, Detroit, MI 48201, USA. Tel: 1-313-576-4492. E-mail: Rishia@Karmanos.org

Received: December 17, 2012 Accepted: January 16, 2013 Online Published: January 29, 2013

doi:10.5539/jmbr.v3n1p1 URL: http://dx.doi.org/10.5539/jmbr.v3n1p1

\begin{abstract}
Malignant pleural mesothelioma (MPM) is a neoplasm arising from the mesothelial cells that line the thoracic pleura. Many factors such as asbestos, genetic predisposition, Simian Virus 40 (SV40) and radiation have been linked to MPM. Although, roles of osteonectin (SPARC) in various cancers including peritoneal MM have previously been studied, its involvement in development of MPM remains to be established. Our RT-PCR and Western blot analysis revealed elevated levels of osteonectin in archived MPM compared to normal peritoneum. We next generated Osteonectin-expressing stable cell lines derived from immortalized mesothelial Met5A cells. In addition, osteonectin expression was knocked-down by stable expression of osteonectin antisense in a patient-derived MPM cell line H2714. The osteonectin-expressing Met5A cells elicited faster migration rates when compared with their vector-expressing controls. Depletion of osteonectin, on the other hand, resulted in a slower migration rate of the MPM cells when compared with their vector-expressing counterparts. Expression of osteonectin also resulted in increased adhesion of the Met5A cells to collagen I, fibronectin and Laminin-coated plates while their adhesion to the collagen IV coated plates was decreased. Interestingly, knock-down of Osteonectin in MPM cells failed to influence their adhesion properties. Finally, we conducted in vitro invasion assays to determine whether osteonectin expression modulated invasive properties of these cells. Osteonectin expression in Met5A cells resulted in significant increase in their invasive properties while loss of osteonectin in MPM cells interfered with their abilities to invade. Taken together, our studies demonstrate that osteonectin regulates MPM cell adhesion, migration, and invasion properties, and therefore is an important regulator of MPM development and progression.
\end{abstract}

Keywords: malignant pleural mesothelioma, osteonectin, Met5A cells, RT-PCR

\section{Introduction}

Malignant pleural mesothelioma (MPM) is a neoplasm that arises from the mesothelial cells lining the pleura. About 2000-3000 new cases are diagnosed each year. Exposure to mineral fibers such as asbestos and erionite has been associated with increased incidence of MPM in men during the first half of the $20^{\text {th }}$ century. However the MPM incidence rate in women remained almost unchanged even though women were also exposed to asbestos through their occupation and second hand exposure (Carbone et al., 2012). Some initial molecular evidence based studies cite the role of sex hormones and their receptors for this discrepancy (Chua et al., 2009; Pinton et al., 2009). Asbestos carcinogenesis is caused, in part, by chronic inflammation due to deposition of asbestos fibers and consequent release of pro-inflammatory molecules such as HMGB-1 (Yang et al., 2010). At the molecular level, asbestos causes DNA alteration by interfering with chromosomal segregation during mitosis (Olofsson \& Mark, 1989) and by inducing mesothelial cells and macrophages to release mutagenic oxygen and 
nitrogen species (Xu, Zhou, Yu, \& Hei, 2002), and thereby promoting survival of the cells with chromosomal mutations. Asbestos does not count for all the MPMs in men and women. About 50-80\% of MPM in men and $20-30 \%$ of MPM in women are due to asbestos exposure. The association of other cofactors such as genetic predisposition, Simian Virus 40 (SV40) and radiation has been linked to MPM in addition to asbestos (Carbone et al., 2012).

Secreted protein acidic and rich in cysteine, SPARC (also known as osteonectin; or basement-membrane-40, $\mathrm{BM}-40$ ) is a $32-\mathrm{kDa}$ multifunctional matricellular glycoprotein. The gene encoding osteonectin is located on human chromosome 5q31-q33, and contains 10 exons spanning 34.6kb (Koukourakis et al., 2003). It is highly conserved through the evolution. There are a total of seven members within the osteonectin family. All members of this protein family share three similar domains (Tai \& Tang, 2008). By binding to structural matrix proteins such as collagen and vitronectin, it functions in mediating cell-ECM interactions (Brekken \& Sage, 2000). However, it does not have a role in structural stability of the ECM. It inhibits cell proliferation in a cell-type-dependent manner (Funk \& Sage, 1993), regulates growth factor activity and inhibits cell adhesion and therefore it participates in physiological processes, where change in ECM and cell mobilization is required (Rivera, Bradshaw, \& Brekken, 2011; Sweetwyne et al., 2004). Examples of such functions include bone mineralization (Termine et al., 1981), tissue remodeling (Tremble, Lane, Sage, \& Werb, 1993; Alvarez et al., 2005) and morphogenesis (Motamed \& Sage, 1998). Osteonectin plays a role in tumor initiation and progression through its counter adhesive properties (Sage \& Bornstein, 1991; Tai \& Tang, 2008) and ability to support migration (Campo McKnight, Sosnoski, Koblinski, \& Gay, 2006). In this context, osteonectin has been found to influence matrix remodeling via metalloproteinases (Tremble et al., 1993), cells shape and proliferation through its interaction with various growth factors (Yan \& Sage, 1999), and has an ability to settle a chronic low inflammatory state (Sangaletti et al., 2005; Alvarez et al., 2005; Sangaletti, Stoppacciaro, Guiducci, Torrisi, \& Colombo, 2003). Although many studies have described the role of osteonectin in a variety of cancers, its role in tumorigenesis is complex and often dependent on the tissue or cell types involved. Osteonectin is differentially expressed in cancer tissue and surrounding stroma (Siddiq, Sarkar, Wali, Pass, \& Lonardo, 2004) and consequently has different functions (Chlenski et al., 2006; Chlenski et al., 2007). High osteonectin expression in tumor cells has been correlated with metastasis, poor host survival and enhanced tumor growth in many cancers (F. Ledda et al., 1997; Schultz, Lemke, Ge, Golembieski, \& Rempel, 2002; Kato et al., 2005; Thomas, True, Bassuk, Lange, \& Vessella, 2000). Stromal osteonectin on the other hand has dual role in tumorigenesis. It inhibits angiogenesis in some cancers (Chlenski et al., 2006), while serving as an indicator of poor prognosis in others (N. Sato et al., 2003; Rempel, Ge, \& Gutierrez, 1999; Derosa et al., 2012). Higher levels of osteonectin have been reported in melanoma (F. Ledda et al., 1997), glioblastoma (Rempel et al., 1998), Medulloblastoma (Bhoopathi, Gondi, Gujrati, Dinh, \& Lakka, 2011), breast (Lien et al., 2007), colorectal cancer (Chew et al., 2011) and lung cancers (Siddiq et al., 2004). Lower levels of osteonectin due mainly to its promoter hypermethylation have been described in ovarian (Yiu et al., 2001), pancreatic (Puolakkainen, Brekken, Muneer, \& Sage, 2004), acute mylogenous leukemia (DiMartino et al., 2006). Therefore osteonectin can support functions of tumor initiating or promoting genes in certain malignancies while it can also function as a tumor suppressor in other cancers. Many studies have described the role of osteonectin in different cancers including peritoneal MM. Its role in development of MPM is yet to be studied.

Due to the long latency period between first asbestos exposure and occurrence of the disease, the continued increase in MPM related mortality is predicted to last. The median survival time for MPM patients are between 8 and 18 months despite multimodality treatment options. Although recent clinical trials show some promise, MPM continues to be a serious health issue. Therefore, new and effective strategies for better management and treatment of this disease are urgently warranted. Such novel treatment strategies will provide hope for the medical community and patients diagnosed with MPM. New evidence based treatment options can be achieved if data explaining the disease mechanism is available. Here we investigated the molecular mechanisms by which osteonectin regulates MPM growth to better define its roles in biology and development of MPM.

\section{Materials and Methods}

\subsection{Cell Lines and Reagents}

Two cell lines, Met5A, generated from normal mesothelial cells and immortalized with SV40 large T-antigen and $\mathrm{H} 2714$ derived from a MPM patient, were used in our study for transfecting sense and anti-sense osteonectin respectively. Met5A was maintained in LHCMM (Biofluid) and H2714 was maintained in RPMI 1640 (HyClone) supplemented with $100 \mathrm{units} / \mathrm{ml}$ penicillin, $100 \mu \mathrm{g} / \mathrm{ml}$ streptomycine, $4 \mathrm{mM} \mathrm{L}$-glutamine and $10 \%$ fetal calf serum (HyClone) under $7.5 \% \mathrm{CO}_{2}$ at $37^{\circ} \mathrm{C}$. The cultures were passaged weekly. Antibody against SPARC was 
purchased from Haematologic Technologies, Inc., Essex Jct., and VT. Secondary antimouse IgG-conjugated with horseradish peroxidase was bought from Santa Cruz Biotechnology, Santa Cruz, CA.

\subsection{RNA Preparation, Reverse Transcription, and Cloning of Osteonectin cDNA}

RNA was isolated using Trizol reagent from Life technologies Inc (Rockville, MD). Cells grown in monolayer at sub-confluency level and frozen tumor samples were lysed in Trizol, extracted in chloroform and precipitated with isopropanol. $3 \mu \mathrm{g}$ poly (A)+ RNA was reverse transcribed with superscriptII reverse transcriptase (Life Technologies Inc, Rockville, MD) using oligo(dt) 12-18 $_{18}$ primers (Life Technologies, Rockville, MD) into first-strand cDNA according to the manufacturer's instructions. The first strand cDNA was then utilized as template for a PCR reaction using 5' and 3' primers (Forward Primer 'GAGGGTTCCCAGCACCATG 3', Reverse Primer 5'AGGGGAGGGTTAAAGAGAG 3'). PCR product was analyzed by agarose gel electrophoresis, the amplified DNA purified, and subcloned in PCRII vector with the advantage of TA cloning system. A number of recombinant plasmids were isolated and cDNA inserts were sequenced to ascertain validity of osteonectin-encoding open reading frame. Osteonectin cDNA was then excised from recombinant PCRII using BstXI and then sub-cloned into BstXI digested pcDNA3.1 expression vector (InVitrogen, Inc.). A number of recombinant pcDNA3.1 plasmids were isolated followed by restriction mapping to obtain constructs harboring sense and anti-sense orientations of osteonectin cDNA.

\subsection{Generation of Osteonectin Stable Transfactants}

We used Lipofectamine (Life Technologies Inc., Rockville, MD) to introduce recombinant pcDNA3.1 plasmids into human mesothelial Met5A as well as MPM cells. Transfections were performed according to the manufacturer's protocol. Briefly, equal numbers $\left(1.5 \times 10^{5}\right)$ of cells were seeded $48 \mathrm{~h}$ prior to transfection, the medium was replaced with fresh serum-free medium and the cells were transfected with 1 to $2 \mu \mathrm{g}$ of respective recombinant plasmid DNAs. Following $3 \mathrm{~h}$ incubation with the transfection solution, cells were washed in PBS and replenished with serum containing medium ( $10 \%$ fetal calf Serum). Forty eight hour later G418 (Calbiochem) was added at concentration of $200 \mu \mathrm{g} / \mathrm{ml}$, and selection for stable transfectants continued for 3-4 weeks. Multiple, single colonies were isolated using cloning cylinders and expanded under G418. Only one clone each from sense and anti-sense transfection experiment was then used for subsequent experiments. For negative controls cell were transfected with pcDNA3.1 plasmid only.

\subsection{Genomic DNA isolation and Genomic PCR}

To confirm the integration of osteonectin in the genome of transfected cells, genomic DNA was isolated from the transfected cells and integrated vector plasmid DNA was amplified using PCR primers that span segment of the vector. DNA was isolated using puregene ${ }^{\mathrm{TM}}$ DNA purification kit from Gentra systems (Minneapolis, MN). Briefly, 1 to 2 million cells was lysed in lysis buffer. RNA was removed from the cell lysates by treating with RNAse A. Contaminant proteins were removed by adding protein precipitation solution. DNA was precipitated with $100 \%$ isopropanol. DNA pellet was hydrated overnight at room temperature and stored at $-80^{\circ} \mathrm{C}$. $100 \mathrm{ng}$ genomic DNA was PCR amplified with primer pairs 5'CGGGACTTTCCAAAATGTCG3' and 5'CAACAGATGGCTGGCAACTA3' that span pcDNA3.1. DNA was amplified using 2.5U Taq Gold from Applied Biosystems (Fostercity, CA). The $50 \mu \mathrm{l}$ amplification reaction mixture contained the template, $400 \mathrm{ng}$ primer, $10 \mathrm{mM}$ dNTP and $25 \mathrm{mM} \mathrm{MgCl}_{2}$ and the manufacturer's recommended buffer. Before amplification, Taq Gold was activated by heating at $95^{\circ} \mathrm{C}$ for $10 \mathrm{~min}$. DNA was then amplified with each amplification cycle consisting of a denaturation step at $95^{\circ} \mathrm{C}$ for $1 \mathrm{~min}$, an annealing step at $55^{\circ} \mathrm{C}$ for $1 \mathrm{~min}$ and an extension step at $72^{\circ} \mathrm{C}$ for $1 \mathrm{~min}$. Each amplification cycle was repeated 35 times with a final extension at $72^{\circ} \mathrm{C}$ for 5 min. Amplification products were then analyzed by agarose gel electrophoresis using a $2 \%$ agarose gel containing ethidium bromide.

\subsection{Real-Time PCR}

For quantitative real time PCR analysis the ABI prism 7700 sequence detector (Applied Biosystems Fostercity, Ca) was used. Briefly $1 \mu \mathrm{l}$ c-DNA was amplified using SYBR green PCR master mix in a $50 \mu \mathrm{l}$ reaction (Applied Biosystems Fostercity, Ca). The $50 \mu \mathrm{l}$ reaction contained $400 \mathrm{ng}$ each of forward and reverse primers specific each for sense and anti-sense osteonectin. To ensure the fidelity of mRNA extraction and reverse transcription all samples were amplified with $18 \mathrm{~S}$ rRNA specific primers and normalized to 18S rRNA levels. Each mRNA and control samples were amplified in triplicate. The amplification conditions were $2 \mathrm{~min}$ at $50^{\circ} \mathrm{C}$, $10 \mathrm{~min}$ at $95^{\circ} \mathrm{C}$ and then 40 cycles of $95^{\circ} \mathrm{C} 15 \mathrm{sec}, 60^{\circ} \mathrm{C} 1 \mathrm{~min}$. Data were analyzed using v.1.7 software provided by PE Biosystems. 


\subsection{Protein Isolation and Western Blot Analyses}

Cells that were grown in monolayer at $70 \%$ confluency or the frozen tumor samples were lysed in RIPA buffer (50 mM Tris-Hcl pH 7.5, $150 \mathrm{mM} \mathrm{Nacl,} \mathrm{0.1 \%} \mathrm{SDS,} \mathrm{1.0 \%} \mathrm{nonidet} \mathrm{P40,} \mathrm{0.5 \%} \mathrm{sodiumdeoxycholate,} 4 \mu \mathrm{g} / \mathrm{ml}$ aprotinin, $100 \mu \mathrm{g} / \mathrm{ml}$ leupeptin, $1 \mathrm{mM}$ Na-orthovanadate, $0.1 \mathrm{mg} / \mathrm{ml} \mathrm{PMSF}$ ) on ice. The lysed suspensions were then centrifuged at $12,000 \mathrm{rpm}$ for $10 \mathrm{~min}$ at $4{ }^{\circ} \mathrm{C}$ and the supernatants were collected, vortexed, aliquoted and stored at $-80^{\circ} \mathrm{C}$ until used. The protein content was determined using Bio-Rad Dc protein assay kit (BioRad Laboratories Inc., Hercules, CA). For western blot analyses, $50 \mu \mathrm{g}$ total protein from each specimen was resolved on a $15 \%$ SDS-PAGE gel under reducing conditions, transferred to Hybond-C super membrane (Amersham Life Science, Piscataway, NJ) The membranes were blocked for $1 \mathrm{hr}$ in $5 \%$ milk, followed by incubation with mouse anti-human osteonectin primary antibodies (Haematologic Technologies, Inc., Essex Jct., VT) for one hour. The membranes were then incubated with secondary antimouse IgG-conjugated with horseradish peroxidase (1:1000) dilution, Santa Cruz Biotechnology, Santa Cruz, CA) for additional one hour. The membranes were then subjected to ECL (Amersham Life Science, Piscataway, NJ), and autoradiographic signals were quantified by scanning followed by analysis with NIH image software.

\subsection{Cell Cycle Analysis}

Cells transfected with vector plasmid or plasmid encoding antisense-osteonectin were plated at equal density. 24 hours later, the cells were washed in PBS and allowed to synchronize in serum-free media for $72 \mathrm{~h}$. The serum-starved cultures were replenished with $10 \%$ serum containing RPMI media and cells were allowed to re-enter the proliferation cycle. Cells were harvested following 24,48 and $72 \mathrm{~h}$ of serum addition, and fixed in $70 \%$ ice cold ethanol overnight at $4^{\circ} \mathrm{C}$. For flow cytometric analysis, the fixed cells were resuspended in $500 \mu \mathrm{l}$ PBS with $0.5 \%$ triton X-100. To remove aggregates, fixed cells were treated with RNAseI at a final concentration of $40 \mu \mathrm{g} / \mathrm{ml}$ for $30 \mathrm{~min}$ at $37^{\circ} \mathrm{C}$. Cells were then stained with $25 \mu \mathrm{g} / \mathrm{ml}$ propidium iodide for $1 \mathrm{~h}$ at room temperature. Stained cells were counted on a Becton Dickinson FACScan. About $15 \times 10^{3}$ cells were analyzed for each time interval. The DNA content profiles were analyzed with Cellquest from Becton Dickinson.

\subsection{Migration Assay}

Migration assay was performed essentially as described before (Dhanesuan, Sharp, Blick, Price, \& Thompson, 2002) with minor modifications using the stable cell lines that express sense or antisense osteonectin. Briefly $5 \times 10^{4}$ cells were seeded in complete RPMI media in 6 well dishes. The cells were grown for $72 \mathrm{~h}$ under $5 \% \mathrm{CO}_{2}$ at $37^{\circ} \mathrm{C}$ to reach $70 \%$ confluency. After $72 \mathrm{~h}$ an incision was then made through the middle of the well with a sterile $1 \mathrm{ml}$ blue pipette tip. The detached cells produced by the incision were removed by washing the plates twice with PBS. Fresh complete RPMI was then added and cells were allowed to grow. The widths of the incisions were photographed at 0,48 and $72 \mathrm{~h}$ for cells expressing osteonectin cDNA in sense orientation, while the cells expressing anti-sense orientation of the osteonectin cDNA were photographed at 0,18 , and $36 \mathrm{~h}$ time periods. Marking was made at the bottom of the plate at $0 \mathrm{~h}$ to measure incision width at the same spot every time.

\subsection{Adhesion Assay}

Adhesion assay was performed in 6 well tissue culture plates according to previously published methods (Said \& Motamed, 2005) with minor modification. Briefly plates were pre-coated with collagen I, collagen IV, Laminin and Fibronectin plates. A $5 \times 10^{4}$ cells/well were seeded in the coated plates and incubated at $37^{\circ} \mathrm{C} / 5 \% \mathrm{CO}_{2}$. After an hour of incubation, plates were gently washed in PBS. Attached cells were stained and fixed in $0.2 \%$ crystal violet in $\mathrm{MetOH}$ for $15 \mathrm{~min}$. Stained plates were washed under running water, dried and photographed. Studies were done in triplicates per experimental condition. Attachment was quantified by solubilizing the attached cells in $1 \%$ SDS and taking absorbance at $540 \mathrm{~nm}$.

\subsection{Invasion Assay}

Invasion assay was performed using Cell Invasion Assay kit (Chemicon International, Temecula, CA). Cells were first grown to subconfluence as monolayer, harvested and suspended at a concentration of $0.5 \times 10^{6}$ cells $/ \mathrm{ml}$ in serum free RPMI medium. A $300 \mu \mathrm{l}$ cell suspension was then placed in the upper chamber of a polycarbonate insert that contained an $8 \mu \mathrm{m}$ pore size polycarbonate membrane, pre-coated with a thin layer of extracellular matrix (ECM). Before the cells were placed, the ECM inside the inserts were pre-equilibrated with the serum free RPMI for an hour. The inserts were then placed in 24 well tissue culture plates. As a chemo attractant, 500 $\mu \mathrm{RPMI}$ containing $10 \%$ serum was then added to the outside of the insert. The cells were incubated under $5 \%$ $\mathrm{CO}_{2}$ at $37^{\circ} \mathrm{C}$ for $72 \mathrm{~h}$. Invasive cells migrated through the ECM layer and remained attached to the bottom of the polycarbonate membrane. Using a cotton-tipped swab, non-invading cells as well as the ECM matrix gel were 
removed from the interior of the inserts. Invasive cells attached to the underside of the inserts were then stained by dipping the bottom part of the inserts in the staining solution provided with the kit. Stained cells were counted with an inverted microscope equipped with camera. All assays were done in triplicates and the results were expressed as the mean \pm SEM.

\section{Results}

\subsection{MPM Tumor Tissues Express Elevated Levels of Osteonectin RNA and Protein}

RT-PCR analysis showed increased osteonectin RNA expression in tumor tissue compared to normal pleura (Figure 1A). The tumor specimens were next analyzed for presence of osteonectin protein by western blotting as detailed in methods. Consistent with the RT-PCR analysis, all the MPM tumors showed presence of osteonectin while minimal to absent levels of osteonectin was noted in the normal pleura (Figure 1B). Quantitative analysis of the blot with NIH image soft-ware revealed up to 7.6 fold increase in osteonectin protein in certain tumor tissues when compared with osteonectin levels in the sample from normal pleura (Figure 1C).

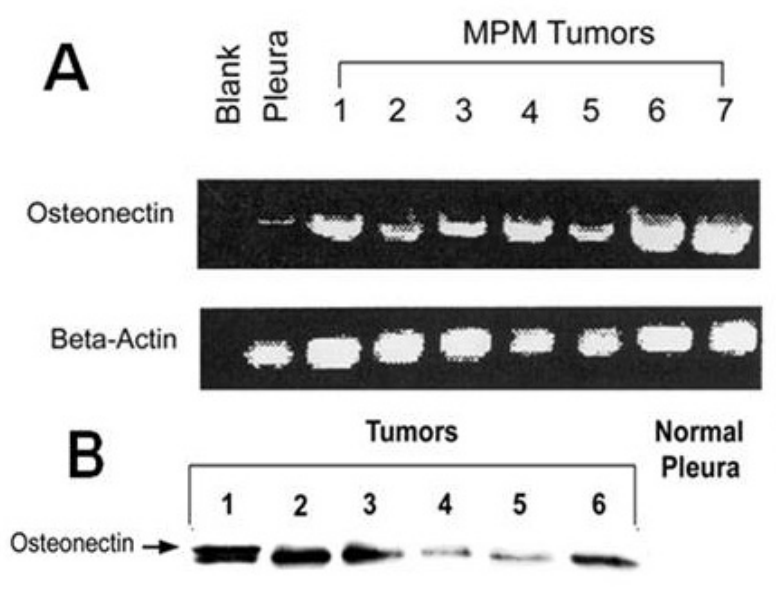

Beta-Actin $\rightarrow-\cdots-\cdots$

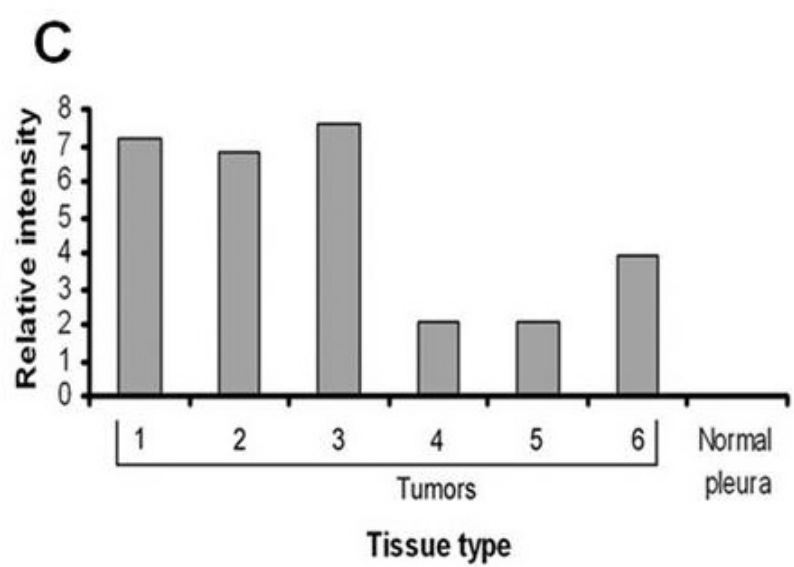

Tissue type

Figure 1. Osteonectin RNA and protein levels in different MPM tumors

(A) Gel showing osteonectin RNA expression in MPM tumors. The data represents one of the three independent experiment replicates. Equal amount of RNA from tumors were reverse transcribed and amplified with osteonectin and Beta-actin specific primers. An aliquot of the PCR products were run on agarose gel and visualized with ethidium bromide. From left to right, blank (no cDNA was used for PCR), pleura, Lane 1-7, different MPM tumors. (B) Representative (one of three replicates) western blot shows protein levels in different MPM tumors. The proteins were transferred to Hybond-C super membrane and osteonectin specific antibody was used to probe the blots. From left to right, Lane 1-6, protein levels in different MPM tumors, normal pleura. The blot was reprobed with Beta-actin specific antibody to assess the loading accuracy and used as an internal control. (C) Differential expression of osteonectin protein in MPM tumors and normal pleura. The autoradiographic signals from blot in panel B were quantified by NIH image software. All protein levels were adjusted relative to beta-actin level. From left to right, Lane 1 to 6, MPM tumors, normal pleura.

\subsection{Ectopic Expression or Knock-Down of Osteonectin Alters Biological Properties of MPM Cells}

To test the extent perturbation of osteonectin levels altered biological properties of the immortalized mesothelial as well as the MPM cells, we first generated and characterized several stable cell lines that harbored expression plasmids encoding osteonectin sense or antisense cDNAs. The osteonectin cDNA was PCR amplified, and subcloned in the pcDNA3.1 vector as described in methods. For osteonectin overexpression, the recombinant plasmid having osteonectin cDNA in the sense orientation was transfected into to the SV40 large T-antigen-immortalized normal mesothelial Met5A cells followed by isolation of stable cell lines as detailed in methods. The levels of osteonectin were analyzed by western blotting and its expression in a representative subline is shown in Figure 2A. Expression of osteonectin cDNA resulted in a 1.8-fold increase in osteonectin 
levels. For knock-down of the oesteonectin, the recombinant plasmid having anti-sense orientation of the osteonectin cDNA was transfected into H2714 MPM cells. Stable sublines expressing osteonectin antisense were isolated and characterized as in methods. Figure 2B shows integration of the antisense construct of a representative stable subline as revealed by PCR amplification and subsequent sequencing of a $1.4 \mathrm{~kb}$ chimeric fragment containing part of vector plasmid and full-length osteonectin cDNA. The vector control transfected cell line however yielded an expected 300bp PCR product. The levels of osteonectin were further analyzed by western blotting and were found to be significantly reduced in the subline stably expressing anti-sense construct (Figure 2C). Stable expression of recombinant plasmid encoding osteonectin antisense resulted in $\sim 8.2$-fold lower levels of osteonectin when compared with the vector-transfected control.

We next utilized the cells having either elevated or depleted levels of osteonectin to study the role of this molecule in cellular remodeling in vitro. As a first step, we performed wound healing assay. The ability of the cells to close monolayer wound was monitored over a $72 \mathrm{~h}$ period in the case of osteonectin-overexpressing cells while anti-sense expressing H2714 MPM cells were monitored over a period of $36 \mathrm{~h}$. Results of the representative migration assays are shown in Figure 3. Overexpression of osteonectin resulted in accelerated migration of the cells in to the area of the incision (Figure 3A). Knock-down of osteonectin on the other hand caused a slower migration rate compared to the vector expressing cells.

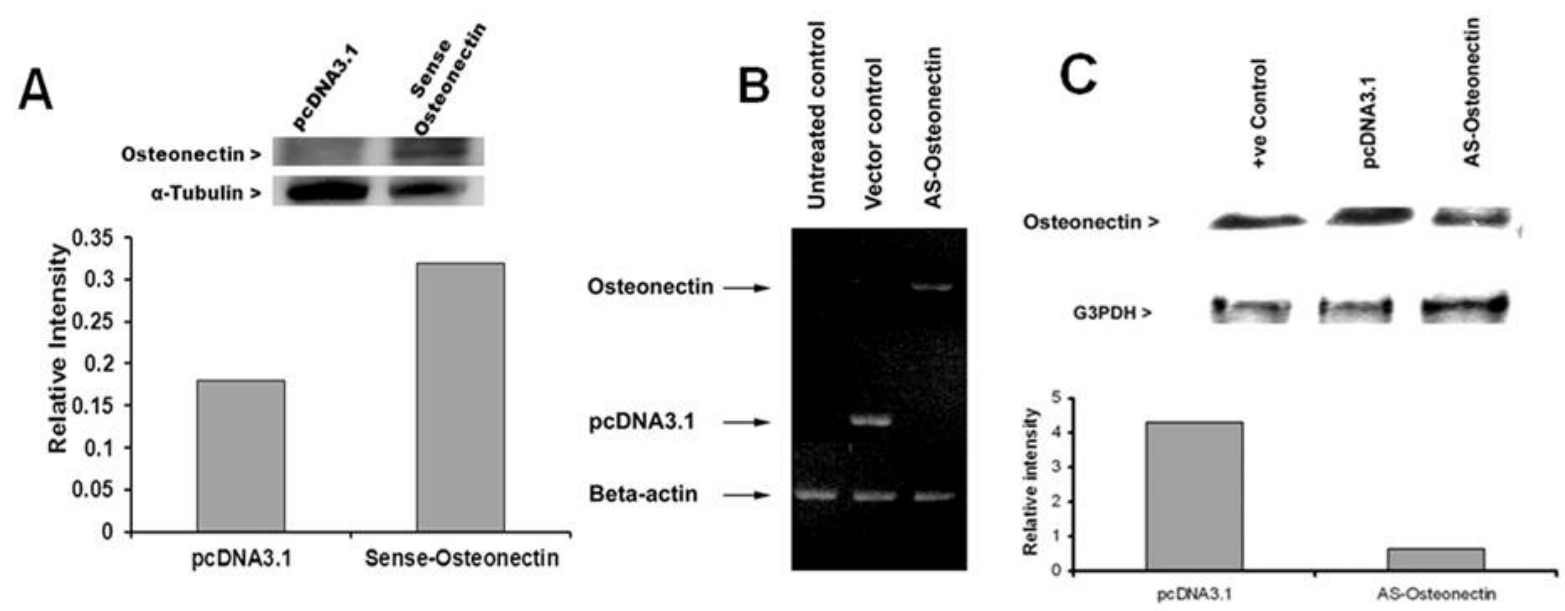

Figure 2. Alteration of osteonectin levels in transfected cells

(A) Real time PCR analysis of osteonectin levels in pcDNA 3.1 and sense osteonectin transfected cells. cDNA was amplified using SYBER green PCR master mix. Alpha-tubulin was used as an internal control. Data was analyzed using v.1.7 provided by the PE systems and relative intensity plotted. (B) Integration of antisenseosteonectin in transfected cells. Isolation of the genomic DNAs from the vector or antisense-transfected cells, and subsequent PCR analysis was carried out as detailed in methods. In antisensense-osteonectin transfected cells a $1.4 \mathrm{~kb}$ band specific for osteonectin $(1.1 \mathrm{~kb})+$ surrounding pcDNA 3.1 (300bp) was amplified. To assess loading, genomic DNA was amplified with beta-actin specific primers. The integration of sense construct was similarly verified (data not shown). (C) Real-Time PCR analysis reveal decrease in osteonectin level in antisense osteonectin transfected cells compared to pcDNA 3.1 transfected counterparts. The isolation of genomic DNA and the real time PCR analysis were carried out essentially as in panel A except that G3PDH was used as an internal control. RNA from a tumor sample was used as a positive control. Data was analyzed using v.1.7 provided by the PE systems and relative intensity plotted in the histogram. 
A

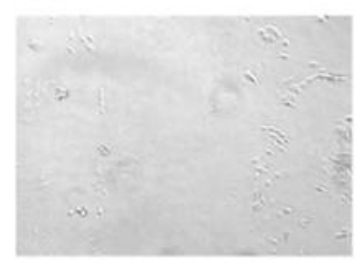

pcDNA3.1 (0 hr)

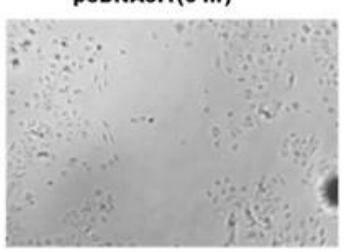

pcDNA3.1(48 hr)

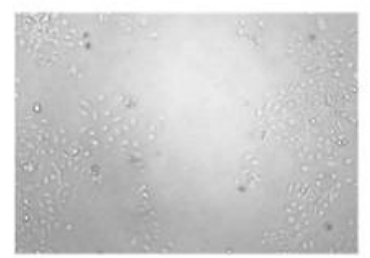

pcDNA3.1(72 hr)

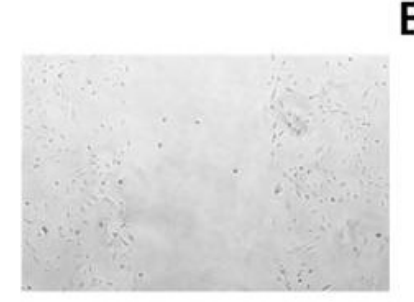

Sense Osteonectin (Ohr)

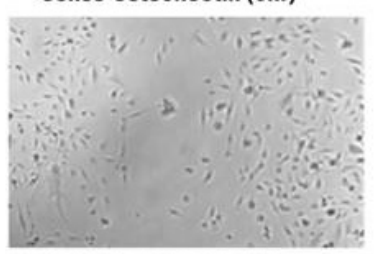

Sense Osteonectin (48hr)

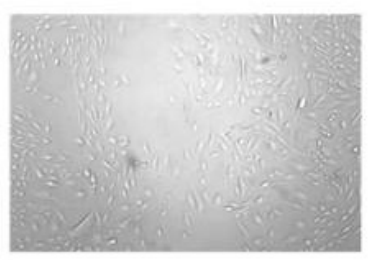

Sense Osteonectin (72 hr)
B

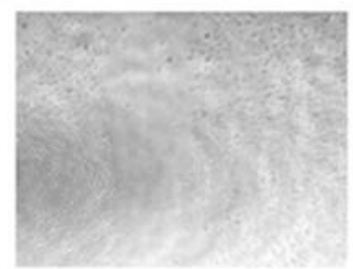

PCDNA 3.1 (0hr)

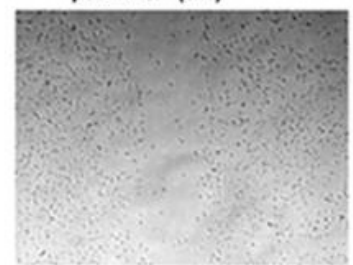

peDNA 3.1 (18hr)

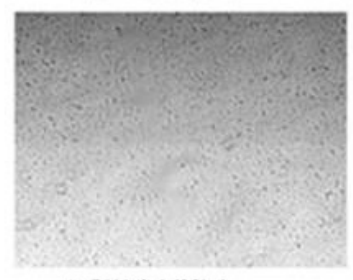

PCDNA 3.1 (36hr)

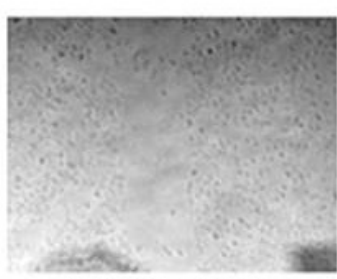

AS-Osteonectin (Ohr)

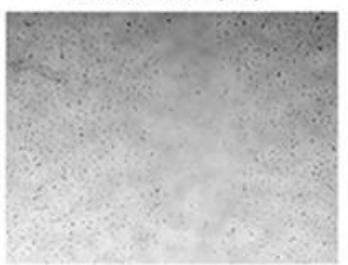

AS-Osteonectin (18hr)

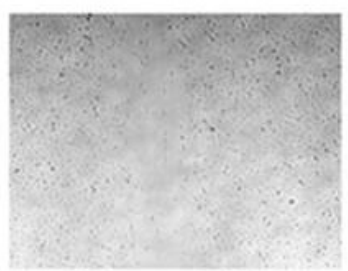

AS-Osteonectin (36hr)

Figure 3. Osteonectin expression alters cell migration

(A) Migration assay of sense osteonectin tansfected cells and their respective vector transfected counterparts. A wound was created on a subconfluent culture of transfected cells and wound closure was measured as in methods. (B) Migration assay of antisense osteonectin tansfected cell lines. Similar to the experiment in panel A, a wound was created on a subconfluent culture of antisense transfected cells and migration of cells into the wound were monitored as above.

Since wound closure often depends on both proliferation and migration, to delineate the effect of proliferation on wound healing, we then performed cell cycle analysis on antisense osteonectin trasfected H2714 cells. Flow cytometry analysis at various time intervals revealed a relatively higher percentage of cells in the $\mathrm{S}$ and $\mathrm{G} 2 / \mathrm{M}$ phase in the antisense transfected cells when compared with their vector-transfected counterparts (Figure 4). Although osteonectin depletion induced significant alterations in the cell cycle phase distribution of the cells, it appears unlikely that the slower migration of these cells following knock-down of osteonectin involved altered cell proliferation. Rather, our current data would suggest that osteonectin likely regulates biological properties of MPM cell migration. 


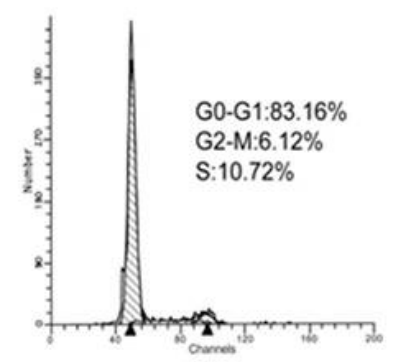

pcDNA3.1 (Ohr)

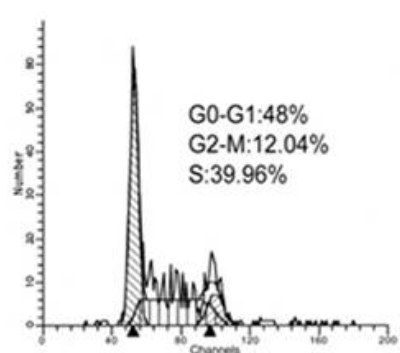

pcDNA3.1 (24hr)

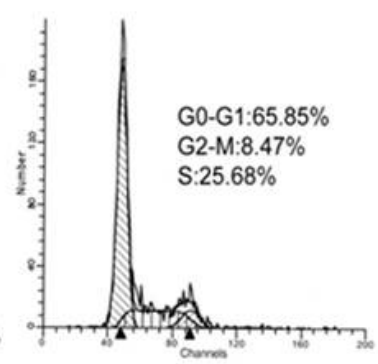

pcDNA3.1 (48hr)

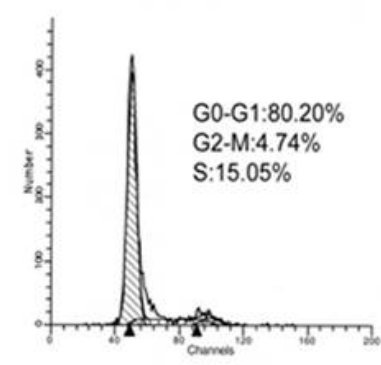

pcDNA3.1 (72hr)

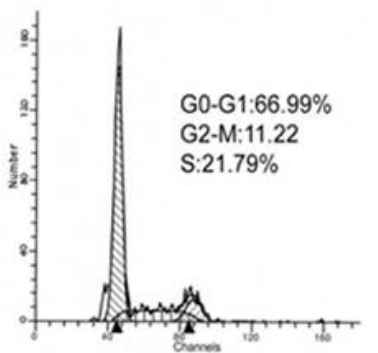

AS-Osteonectin (Ohr)

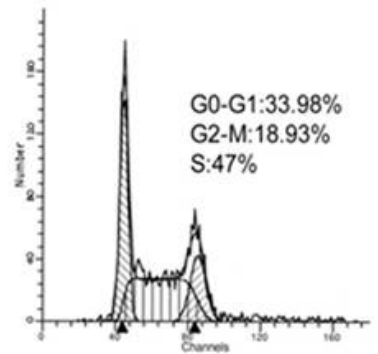

AS-Osteonectin (24hr)

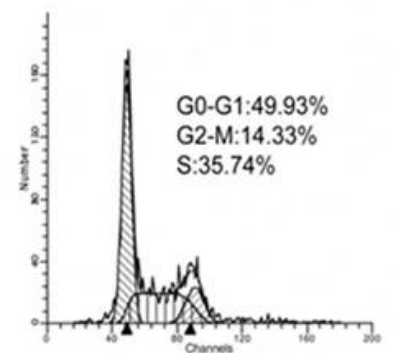

AS-Osteonectin (48hr)

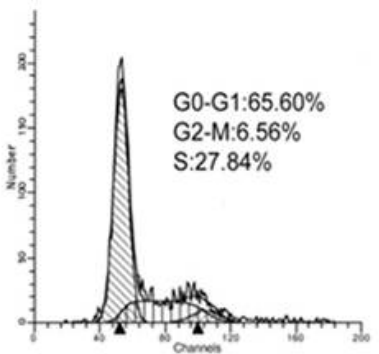

As-Osteonectin (72hr)

Figure 4. Osteonectin alters cellular migration properties independent of cell cycle alterations

Representative FACS analysis of pcDNA 3.1 and antisense osteonectin transfected cell line is shown. The various cell cycle population corresponding to individual cytofluorimetry peaks are indicated as inserts in each plot. Even though more cells are present in S-phase in anti-sense transfected cell line at different time intervals, the cells displayed attenuated migration in the wound healing assay suggesting that their migration properties were unlikely influenced by the alterations in their cell cycle phase distribution/cell division.

In light of the fact that loss of adhesion is often a pre-requisite for tumor cell invasion, and the fact that a number of earlier reports have suggested an ability/property of osteonectin to influence adhesion (Said \& Motamed, 2005; Campo McKnight et al., 2006), we then investigated the extent osteonectin altered MPM tumor cell adhesion to the various ECM constituents (Collagen I, Fibronectin, Laminin and Collagen IV). Our study revealed, in comparison to the vector transfected cell line, osteonectin over-expressing cells displayed increased adhesion towards various ECM constituents. The maximum adhesion was observed towards collagen I and fibronectin ( $p$ $=0.0001)$ (Figure 5A) followed by laminin $(p=0.0053)$. However, elevated osteonectin resulted in reduced adhesion to collagen IV (not shown). Increasing the level of osteonectin in H2417 cells did not alter their adhesion properties in a statistically significant manner when compared with the vector expressing H2714 cells. 

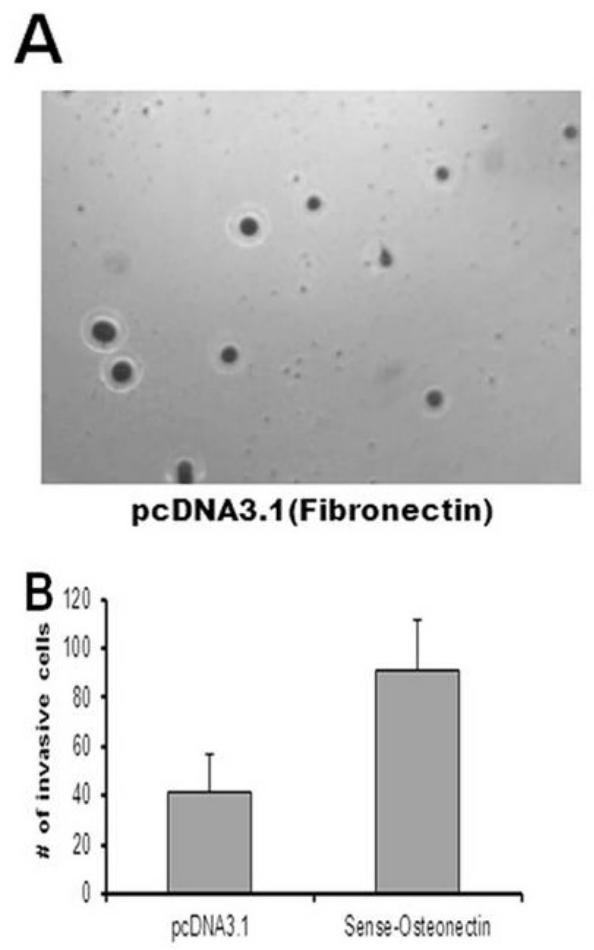
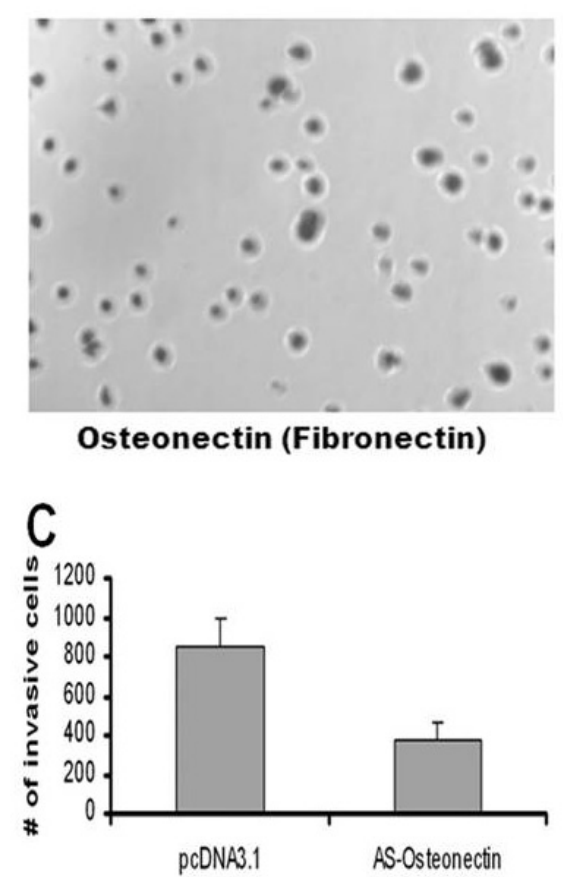

Figure 5. Osteonectin expression alters cell adhesion

(A) Representative image of the differences in adhesion of the osteonectin-overexpressing cells compared with the vector expressing cells. (B) Histogram showing number of invasive cells in osteonectin overexpressing cells and their vector transfected counterpart. (C) Histogram showing number of invasive cells in antisense osteonectin transfected cells and their vector transfected counterpart.

To further study the role of osteonectin in MPM cell invasion, in vitro assays were performed in matrigel coated inserts as described in materials and methods. Results of the invasion assays are shown in Figures 5B and C. Our data revealed up regulation of osteonectin expression in Met-5A cells resulted in 2.2 fold increase in invasion of cells when compared with their vector-transfected counterparts (Figure 5B). However, loss of osteonectin in $\mathrm{H} 2714$ cells resulted in 2.2 fold reduction in invasive properties of these cells in comparison with their vector expressing controls (Figure 5C).

\section{Discussion}

Osteonectin is matrix associated glycoprotein which is abundant in tissues undergoing remodeling. Several studies so far revealed up-regulated osteonectin expression in malignancies of both mesenchymal and epithelial origin. Osteonectin is over-expressed in many cell lines that originated from different malignancies such as glioblastoma (Rempel et al., 1998), melanoma (F. Ledda et al., 1997), prostate and breast cancers (Thomas et al., 2000), as well as the cells that acquire mesenchymal properties (Gilles et al., 1998). Osteonectin has dramatic effect on cell behavior in vitro. The major known functions of osteonectin include anti-adhesive and anti-proliferative effects. The counter-adhesive properties of osteonectin in non-malignant cells led to further exploration of its potential role in tumor invasion and metastasis. The ability of cancer cells to disseminate though requires that the malignant cells first adhere to ECM matrices followed by their invasion of the basement membrane. However, the role osteonectin plays in regulating adhesion and invasion properties is also cell type dependent. Our interest in mesothelioma prompted us to study the genes involved in mesothelioma initiation and progression. Our preliminary data from gene expression array (data not shown) revealed osteonectin was up-regulated in MPM that is further supported by increased osteonectin levels in MPM tumors noted in our current study. Although inconsistent pattern exists in terms of both expression and biological activity of osteonectin, we speculated that better understanding of the mechanism(s) of action of osteonectin may shed light into its role(s) in the processes of tumorigenesis. This prompted us to first clone osteonectin in the sense or antisense orientations and then generates various cell lines that either overexpress or have reduced levels of 
osteonectin. Following transfections, we generated stable cell lines, and characterized them for levels of osteonectin by RT-PCR and western immunoblotting.

As expected, over-expression of osteonectin caused increased migration and invasion in vitro. In a similar assay, knock-down of osteonectin resulted in decreased migration and invasion. Although over-expression of osteonectin interestingly promoted cell interactions with collagen I, fibronectin and laminin, knock-down of osteonectin intriguingly failed to cause significant changes in adhesive properties of the MPM cells. This could be due to the fact that the matrices involved in our experiments do not represent the entire repertoire of "stromal-tumor microenvironment" milieu under which tumor initiation, progression and local spread of MPM takes place within thoracic cavity. Based on the compensatory mechanisms with "osteopontin" being the predominant factor involved in conjunction with "osteonectin", it is likely that differences in the critical threshold levels of endogenous, constitutively active osteonectin within affected pleural space, and the released form of osteonectin in the extracellular space, besides other secretary molecules present in the region, influence interactions with regards to differences observed in adhesion and migratory properties of osteonectin. The extent absence of changes in the adhesive properties of osteonectin-depleted MPM cells is due to altered cellular "compensatory mechanisms" remains to be clarified. Nevertheless, a thorough further investigation will be necessary to explain this discrepancy. Although, overexpression of osteonectin was noted in the case of melanoma (Ledda et al., 1997) and breast cancer cell lines (Gilles et al., 1998), suppression of osteonectin in melanoma cells resulted in significant decrease in in vitro adhesive and invasive capacity of the cells, interfering with the ability of osteonectin-depleted cells to form tumors in vivo. In contrast, ovarian cancer cells that had elevated levels of osteonectin were significantly inhibited in their ability to adhere and invade a number of matrices such as collagen I, collagen IV, vitronectin, fibronectin, hyaluronic acid and laminin (Said \& Motamed, 2005). This was supported by lower rate of intra-peritoneal dissemination of ovarian cancer in osteonectin $+/+$ mice. Similar effect was shown by pancreatic cancer cell grown in osteonectin-/- mice. In case of pancreatic cancer, tumor grown in osteonectin null mice was larger and more prone to metastasize compared to tumor grown in osteonectin+/+ mice (Puolakkainen et al., 2004; Arnold et al., 2008). Later the effect of osteonectin on ovarian cancer was shown to be caused by lowering the cell surface expression of $\alpha_{\mathrm{V}}$-integrin and $\beta 1$ - subunits (Said, Najwer, \& Motamed, 2007). Osteonectin was also shown to be capable of inhibiting the VEGF-induced integrin activation and down-regulation of metalloproteinases such as MMP2 and MMP9 (Said \& Motamed, 2005; Socha et al., 2007). MMP2 can cleave Collagen type IV, which results in degradation of basement membrane and can help in metastasis and tumor progression (Hornebeck, Emonard, Monboisse, \& Bellon, 2002). MMP2 is secreted as an inactive pro-enzyme. It becomes activated after the proteolytic cleavage of its NH2-terminal pro-fragment. (Atkinson et al., 1995; Stetler-Stevenson, 1994). MT1-MMP is another MMP that contributes to MMP2 activation (Lohi \& Keski-Oja, 1995). In vivo major source of MMP2 and MT1-MMP are fibroblasts (Polette, Nawrocki-Raby, Gilles, Clavel, \& Birembaut, 2004). However, up-regulated MMP2 and MT1-MMP have been observed in cases of invasive tumors (Sato \& Seiki, 1996), (Gilles, Polette, Seiki, Birembaut, \& Thompson, 1997). Elevetaed levels of MMP9 have also been found to be associated with increased invasiveness of both the murine and human MPM cells as well as the orthotopic MPM tumors in mice (Servias et al., 2012). In contrast to ovarian cancer cells where osteonectin reduced MMP activity, overexpression of MMP9 in pancreatic cancer cells resulted in a greater cell migration and invasion in vitro. This effect was completely abolished by the addition of osteonectin (Arnold et al., 2008). In cases of prostate cancer, osteonectin induced MMP2 activity and aided prostate cancer cells to metastasize in the bone (Jacob, Webber, Benayahu, \& Kleinman, 1999), while in the ovarian and breast cancer cells, osteonectin and smaller peptide fragments containing its N-terminal region, induced MMP2 activation and their invasive phenotype. The role of osteonectin in invasion was further strengthened by its regulation/promotion of EMT transition (Girotti et al., 2011; Conant, Peng, Evans, Naud, \& Cooper, 2011). Cell cycle analysis using osteonectin over-expressing breast cancer cells showed slower progression to S phase (Dhanesuan et al., 2002). This is consistent with our current observations where knock-down of osteonectin in MPM cells resulted in a greater number of cells in the G2/M and $\mathrm{S}$ phases.

In conclusion we have demonstrated for the first time the role of osteonectin in mesothelioma progression in vitro. We have found that osteonectin is a positive regulator of adhesion to various ECM constituents, invasion and migration, and thus an important transducer of MPM cancer progression. Our proof-of-concept studies therefore warrant further research to elucidate potential of osteonectin as a target for therapeutic intervention in MPM. 


\section{References}

Alvarez, M. J., Prada, F., Salvatierra, E., Bravo, A. I., Lutzky, V. P., Carbone, C., ... Podhajcer, O. L. (2005). Secreted protein acidic and rich in cysteine produced by human melanoma cells modulates polymorphonuclear leukocyte recruitment and antitumor cytotoxic capacity. Cancer Res., 65, 5123-32. http://dx.doi.org/10.1158/0008-5472.CAN-04-1102

Arnold, S., Mira, E., Muneer, S., Korpanty, G., Beck, A. W., Holloway, S. E., ... Brekken, R. A. (2008). Forced expression of MMP9 rescues the loss of angiogenesis and abrogates metastasis of pancreatic tumors triggered by the absence of host SPARC. Exp Biol Med (Maywood), 233, 860-73. http://dx.doi.org/10.3181/0801-RM-12

Atkinson, S. J., Crabbe, T., Cowell, S., Ward, R. V., Butler, M. J., Sato, H., ... Murphy, G. (1995). Intermolecular autolytic cleavage can contribute to the activation of progelatinase A by cell membranes. $J$. Biol. Chem., 270, 30479-85. http://dx.doi.org/10.1074/jbc.270.51.30479

Bhoopathi, P., Gondi, C. S., Gujrati, M., Dinh, D. H., \& Lakka, S. S. (2011). SPARC mediates Src-induced disruption of actin cytoskeleton via inactivation of small GTPases Rho-Rac-Cdc42. Cell Signal, 23, 1978-87. http://dx.doi.org/10.1016/j.cellsig.2011.07.008

Brekken, R. A., \& Sage, E. H. (2000). SPARC, a matricellular protein: at the crossroads of cell-matrix. Matrix Biol., 19, 569-80. http://dx.doi.org/10.1016/S0945-053X(00)00105-0

Campo McKnight, D. A., Sosnoski, D. M., Koblinski, J. E., \& Gay, C. V. (2006). Roles of osteonectin in the migration of breast cancer cells into bone. J. Cell Biochem, 97, 288-302. http://dx.doi.org/10.1002/jcb.20644

Carbone, M., Ly, B. H., Dodson, R. F., Pagano, I., Morris, P. T., Dogan, U. A., .. Yang, H. (2012). Malignant mesothelioma: facts, myths, and hypotheses. J. Cell Physiol, 227, 44-58. http://dx.doi.org/10.1002/jcp.22724

Chew, A., Salama, P., Robbshaw, A., Klopcic, B., Zeps, N., Platell, C., \& Lawrance, I. C. (2011). SPARC, FOXP3, CD8 and CD45 correlation with disease recurrence and long-term disease-free survival in colorectal cancer. PLoS One, 6, e22047. http://dx.doi.org/10.1371/journal.pone.0022047

Chlenski, A., Guerrero, L. J., Yang, Q., Tian, Y., Peddinti, R., Salwen, H. R., \& Cohn, S. L. (2007). SPARC enhances tumor stroma formation and prevents fibroblast activation. Oncogene, 26, 4513-22. http://dx.doi.org/10.1038/sj.onc.1210247

Chlenski, A., Liu, S., Guerrero, L. J., Yang, Q., Tian, Y., Salwen, H. R., ... Cohn, S. L. (2006). SPARC expression is associated with impaired tumor growth, inhibited angiogenesis and changes in the extracellular matrix. Int. J. Cancer, 118, 310-6. http://dx.doi.org/10.1002/ijc.21357

Chua, T. C., Yao, P., Akther, J., Young, L., Bao, S., Samaraweera, U., ... Morris, D. L. (2009). Differential expression of Ki-67 and sex steroid hormone receptors between genders in peritoneal mesothelioma. Pathol. Oncol. Res., 15, 671-8. http://dx.doi.org/10.1007/s12253-009-9170-0

Conant, J. L., Peng, Z., Evans, M. F., Naud, S., \& Cooper, K. (2011). Sarcomatoid renal cell carcinoma is an example of epithelial--mesenchymal transition. J. Clin. Pathol., 64, 1088-92. http://dx.doi.org/10.1136/jclinpath-2011-200216

Derosa, C. A., Furusato, B., Shaheduzzaman, S., Srikantan, V., Wang, Z., Chen, Y., ... Petrovics, G. (2012). Elevated osteonectin/SPARC expression in primary prostate cancer predicts metastatic progression. Prostate Cancer Prostatic Dis., 15, 150-6. http://dx.doi.org/10.1038/pcan.2011.61

Dhanesuan, N., Sharp, J. A., Blick, T., Price, J. T., \& Thompson, E. W. (2002). Doxycycline-inducible expression of SPARC/Osteonectin/BM40 in MDA-MB-231 human breast cancer cells results in growth inhibition. Breast Cancer Res. Treat., 75, 73-85. http://dx.doi.org/10.1023/A:1016536725958

DiMartino, J. F., Lacayo, N. J., Varadi, M., Li, L., Saraiya, C., Ravindranath, Y., ... Dahl, G. V. (2006). Low or absent SPARC expression in acute myeloid leukemia with MLL rearrangements is associated with sensitivity to growth inhibition by exogenous SPARC protein. Leukemia, 20, 426-32. http://dx.doi.org/10.1038/sj.leu.2404102

Funk, S. E., \& Sage, E. H. (1993). Differential effects of SPARC and cationic SPARC peptides on DNA synthesis by endothelial cells and fibroblasts. J. Cell Physiol., 154, 53-63. http://dx.doi.org/10.1002/jcp.1041540108 
Gilles, C., Bassuk, J. A., Pulyaeva, H., Sage, E. H., Foidart, J. M., \& Thompson, E. W. (1998). SPARC/osteonectin induces matrix metalloproteinase 2 activation in human breast cancer cell lines. Cancer Res., 58, 5529-36.

Gilles, C., Polette, M., Seiki, M., Birembaut, P., \& Thompson, E. W. (1997). Implication of collagen type I-induced membrane-type 1-matrix metalloproteinase expression and matrix metalloproteinase-2 activation in the metastatic progression of breast carcinoma. Lab Invest., 76, 651-60.

Girotti, M. R., Fernandez, M., Lopez, J. A., Camafeita, E., Fernandez, E. A., Albar, J. P., ... Llera, A. S. (2011). SPARC promotes cathepsin B-mediated melanoma invasiveness through a collagen I/alpha2beta1 integrin axis. J. Invest. Dermatol, 131, 2438-47. http://dx.doi.org/10.1038/jid.2011.239

Hornebeck, W., Emonard, H., Monboisse, J. C., \& Bellon, G. (2002). Matrix-directed regulation of pericellular proteolysis and tumor progression. Semin. Cancer Biol., 12, 231-41. http://dx.doi.org/10.1016/S1044-579X(02)00026-3

Jacob, K., Webber, M., Benayahu, D., \& Kleinman, H. K. (1999). Osteonectin promotes prostate cancer cell migration and invasion: a possible mechanism for metastasis to bone. Cancer Res., 59, 4453-7.

Kato, Y., Nagashima, Y., Baba, Y., Kawano, T., Furukawa, M., Kubota, A., ... Tsukuda, M. (2005). Expression of SPARC in tongue carcinoma of stage II is associated with poor prognosis: an immunohistochemical study of 86 cases. Int. J. Mol. Med., 16, 263-8.

Koukourakis, M. I., Giatromanolaki, A., Brekken, R. A., Sivridis, E., Gatter, K. C., Harris, A. L., \& Sage, E. H. (2003). Enhanced expression of SPARC/osteonectin in the tumor-associated stroma of non-small cell lung cancer is correlated with markers of hypoxia/acidity and with poor prognosis of patients. Cancer Res., 63, 5376-80.

Ledda, F., Bravo, A. I., Adris, S., Bover, L., Mordoh, J., \& Podhajcer, O. L. (1997). The expression of the secreted protein acidic and rich in cysteine (SPARC) is associated with the neoplastic progression of human melanoma. J. Invest. Dermatol, 108, 210-4. http://dx.doi.org/10.1111/1523-1747.ep12334263

Ledda, M. F., Adris, S., Bravo, A. I., Kairiyama, C., Bover, L., Chernajovsky, Y., ... Podhajcer, O. L. (1997). Suppression of SPARC expression by antisense RNA abrogates the tumorigenicity of human melanoma cells. Nat. Med., 3, 171-6. http://dx.doi.org/10.1038/nm0297-171

Lien, H. C., Hsiao, Y. H., Lin, Y. S., Yao, Y. T., Juan, H. F., Kuo, W. H., ... Hsieh, F. J. (2007). Molecular signatures of metaplastic carcinoma of the breast by large-scale transcriptional profiling: identification of genes potentially related to epithelial-mesenchymal transition. Oncogene, 26, 7859-71. http://dx.doi.org/10.1038/sj.onc.1210593

Lohi, J., \& Keski-Oja, J. (1995). Calcium ionophores decrease pericellular gelatinolytic activity via inhibition of 92-kDa gelatinase expression and decrease of 72-kDa gelatinase activation. J. Biol. Chem., 270, 17602-9. http://dx.doi.org/10.1074/jbc.270.29.17602

Motamed, K., \& Sage, E. H. (1998). SPARC inhibits endothelial cell adhesion but not proliferation through a tyrosine phosphorylation-dependent pathway. J. Cell Biochem, 70, 543-52. http://dx.doi.org/10.1002/(SICI)1097-4644(19980915)70:4<543::AID-JCB10>3.0.CO;2-I

Olofsson, K., \& Mark, J. (1989). Specificity of asbestos-induced chromosomal aberrations in short-term cultured human mesothelial cells. Cancer Genet Cytogenet, 41, 33-9. http://dx.doi.org/10.1016/0165-4608(89)90105-2

Pinton, G., Brunelli, E., Murer, B., Puntoni, R., Puntoni, M., Fennell, D. A., ... Moro, L. (2009). Estrogen receptor-beta affects the prognosis of human malignant mesothelioma. Cancer Res., 69, 4598-604. http://dx.doi.org/10.1158/0008-5472.CAN-08-4523

Polette, M., Nawrocki-Raby, B., Gilles, C., Clavel, C., \& Birembaut, P. (2004). Tumour invasion and matrix metalloproteinases. Crit Rev Oncol Hematol, 49, 179-86. http://dx.doi.org/10.1016/j.critrevonc.2003.10.008

Puolakkainen, P. A., Brekken, R. A., Muneer, S., \& Sage, E. H. (2004). Enhanced growth of pancreatic tumors in SPARC-null mice is associated with decreased deposition of extracellular matrix and reduced tumor cell apoptosis. Mol. Cancer Res., 2, 215-24.

Rempel, S. A., Ge, S., \& Gutierrez, J. A. (1999). SPARC: a potential diagnostic marker of invasive meningiomas. Clin. Cancer Res., 5, 237-41. http://dx.doi.org/10.1097/00005072-199812000-00002 
Rempel, S. A., Golembieski, W. A., Ge, S., Lemke, N., Elisevich, K., Mikkelsen, T., \& Gutierrez, J. A. (1998). SPARC: a signal of astrocytic neoplastic transformation and reactive response in human primary and xenograft gliomas. J. Neuropathol Exp. Neurol., 57, 1112-21.

Rivera, L. B., Bradshaw, A. D., \& Brekken, R. A. (2011). The regulatory function of SPARC in vascular biology. Cell Mol Life Sci., 68, 3165-73. http://dx.doi.org/10.1007/s00018-011-0781-8

Sage, E. H., \& Bornstein, P. (1991). Extracellular proteins that modulate cell-matrix interactions. SPARC, tenascin, and thrombospondin. J. Biol. Chem., 266, 14831-4.

Said, N., \& Motamed, K. (2005). Absence of host-secreted protein acidic and rich in cysteine (SPARC) augments peritoneal ovarian carcinomatosis. Am. J. Pathol., 167, 1739-52. http://dx.doi.org/10.1016/S0002-9440(10)61255-2

Said, N., Najwer, I., \& Motamed, K. (2007). Secreted protein acidic and rich in cysteine (SPARC) inhibits integrin-mediated adhesion and growth factor-dependent survival signaling in ovarian cancer. Am. J. Pathol, 170, 1054-63. http://dx.doi.org/10.2353/ajpath.2007.060903

Said, N., Socha, M. J., Olearczyk, J. J., Elmarakby, A. A., Imig, J. D., \& Motamed, K. (2007). Normalization of the ovarian cancer microenvironment by SPARC. Mol. Cancer Res., 5, 1015-30. http://dx.doi.org/10.1158/1541-7786.MCR-07-0001

Sangaletti, S., Gioiosa, L., Guiducci, C., Rotta, G., Rescigno, M., Stoppacciaro, A., Chiodoni, C., \& Colombo, M. P. (2005). Accelerated dendritic-cell migration and T-cell priming in SPARC-deficient mice. J. Cell Sci., 118, 3685-94. http://dx.doi.org/10.1242/jcs.02474

Sangaletti, S., Stoppacciaro, A., Guiducci, C., Torrisi, M. R., \& Colombo, M. P. (2003). Leukocyte, rather than tumor-produced SPARC, determines stroma and collagen type IV deposition in mammary carcinoma. $J$. Exp. Med., 198, 1475-85. http://dx.doi.org/10.1084/jem.20030202

Sato, H., \& Seiki, M. (1996). Membrane-type matrix metalloproteinases (MT-MMPs) in tumor metastasis. $J$. Biochem, 119, 209-15. http://dx.doi.org/10.1093/oxfordjournals.jbchem.a021223

Sato, N., Fukushima, N., Maehara, N., Matsubayashi, H., Koopmann, J., Su, G. H., ... Goggins, M. (2003). SPARC/osteonectin is a frequent target for aberrant methylation in pancreatic adenocarcinoma and a mediator of tumor-stromal interactions. Oncogene, 22, 5021-30. http://dx.doi.org/10.1038/sj.onc. 1206807

Schultz, C., Lemke, N., Ge, S., Golembieski, W. A., \& Rempel, S. A. (2002). Secreted protein acidic and rich in cysteine promotes glioma invasion and delays tumor growth in vivo. Cancer Res., 62, 6270-7.

Servais, E. L., Colovos, C., Rodriguez, L., Bograd, A. J., Nitadori, J., Sima, C., ... Adusumilli, P. S. (2012). Mesothelin overexpression promotes mesothelioma cell invasion and MMP-9 secretion in an orthotopic mouse model and in epithelioid pleural mesothelioma patients. Clin Cancer Research, 18, 2478-89.

Siddiq, F., Sarkar, F. H., Wali, A., Pass, H. I., \& Lonardo, F. (2004). Increased osteonectin expression is associated with malignant transformation and tumor associated fibrosis in the lung. Lung Cancer, 45, 197-205. http://dx.doi.org/10.1016/j.lungcan.2004.01.020

Stetler-Stevenson, W. G. (1994). Progelatinase A activation during tumor cell invasion. Invasion Metastasis, 14, 259-68.

Sweetwyne, M. T., Brekken, R. A., Workman, G., Bradshaw, A. D., Carbon, J., Siadak, A. W., ... Sage, E. H. (2004). Functional analysis of the matricellular protein SPARC with novel monoclonal antibodies. $J$. Histochem Cytochem, 52, 723-33. http://dx.doi.org/10.1369/jhc.3A6153.2004

Tai, I. T., \& Tang, M. J. (2008). SPARC in cancer biology: its role in cancer progression and potential for therapy. Drug Resist Updat., 11, 231-46. http://dx.doi.org/10.1016/j.drup.2008.08.005

Termine, J. D., Kleinman, H. K., Whitson, S. W., Conn, K. M., McGarvey, M. L., \& Martin, G. R. (1981). Osteonectin, a bone-specific protein linking mineral to collagen. Cell, 26, 99-105. http://dx.doi.org/10.1016/0092-8674(81)90037-4

Thomas, R., True, L. D., Bassuk, J. A., Lange, P. H., \& Vessella, R. L. (2000). Differential expression of osteonectin/SPARC during human prostate cancer progression. Clin. Cancer Res., 6, 1140-9.

Tremble, P. M., Lane, T. F., Sage, E. H., \& Werb, Z. (1993). SPARC, a secreted protein associated with morphogenesis and tissue remodeling, induces expression of metalloproteinases in fibroblasts through a 
novel extracellular matrix-dependent pathway. J. Cell Biol., 121, 1433-44. http://dx.doi.org/10.1083/jcb.121.6.1433

Xu, A., Zhou, H., Yu, D. Z., \& Hei, T. K. (2002). Mechanisms of the genotoxicity of crocidolite asbestos in mammalian cells: implication from mutation patterns induced by reactive oxygen species. Environ Health Perspect, 110, 1003-8. http://dx.doi.org/10.1289/ehp.021101003

Yan, Q., \& Sage, E. H. (1999). SPARC, a matricellular glycoprotein with important biological functions. J. Histochem Cytochem, 47, 1495-506. http://dx.doi.org/10.1177/002215549904701201

Yang, H., Rivera, Z., Jube, S., Nasu, M., Bertino, P., Goparaju, C., ... Carbone, M. (2010). Programmed necrosis induced by asbestos in human mesothelial cells causes high-mobility group box 1 protein release and resultant inflammation. Proc. Natl. Acad. Sci. USA, 107, 12611-6. http://dx.doi.org/10.1073/pnas.1006542107

Yiu, G. K., Chan, W. Y., Ng, S. W., Chan, P. S., Cheung, K. K., Berkowitz, R. S., \& Mok, S. C. (2001). SPARC (secreted protein acidic and rich in cysteine) induces apoptosis in ovarian cancer cells. Am. J. Pathol., 159, 609-22. http://dx.doi.org/10.1016/S0002-9440(10)61732-4 